\title{
EL RECURSO DE PROTECCIÓN EN ASUNTOS AMBIENTALES: CRITERIOS PARA SU PROCEDENCIA POSTINSTITUCIONALIDAD AMBIENTAL (2010-2015)
}

\author{
CONSTITUTIONAL CLAIMS IN ENVIRONMENTAL ISSUES: A \\ PROPOSAL FOR NEW STANDARDS AFTER THE ARRIVAL OF \\ SPECIALIZED AGENCIES AND COURTS (2010-2015)
}

\author{
Arturo Fermandois VöHringer ${ }^{1}$ \\ Teresita Chubretovic Arnaiz ${ }^{2}$
}

\begin{abstract}
RESUMEN: Ante la ausencia de una dogmática clara desde la doctrina y jurisprudencia aún insuficiente, el trabajo propone cuatro criterios precisos para resolver y armonizar la convivencia procesal entre el Recurso de Protección y las acciones propias sustanciadas ante los Tribunales Ambientales. La propuesta se construye desde un análisis de la naturaleza y desarrollo de la acción cautelar del artículo 20 de la Carta Fundamental, en combinación con algunos estándares ya propuestos por la Corte Suprema en sus fallos.
\end{abstract}

Palabras clave: Derecho Constitucional, admisibilidad del recurso de protección, tribunales ambientales, revisión judicial.

ABSTRACT: In the absence of a clear doctrine and insufficiency of legal precedents, this work proposes four precise criteria to solve and harmonize the procedural coexistence of the Concrete Writ of Constitutionality before the Court of Appeals and the actions sustained before de Environmental Courts. The proposal arises from the analysis of the nature and development of the constitutional action of article 20 of the Carta Magna, in combination with some standards already provided by the Supreme Court in its pronouncements.

Key words: Constitutional Law, admissibility of concrete writ of constitutionality, environmental courts, judicial review.

\section{INTRODUCCIÓN}

Cuando no estaban creadas en Chile las institucionalidades laboral, tributaria o medioambiental con sus respectivos tribunales especializados, el espacio procesal del recurso constitucional de protección era evidente: se trataba de una herramienta única, eficaz y casi exclusiva para la protección de los derechos fundamentales comprometidos en esas áreas.

Hoy, en cambio, el panorama es diferente y existen numerosos mecanismos de reclamación que la ley franquea a las persona spara deducir ante a órganos o tribunales especia-

\footnotetext{
1 Abogado, Pontificia Universidad Católica de Chile. Profesor de Derecho Constitucional, Pontificia Universidad Católica de Chile. Máster en Administración Pública, Universidad de Harvard. Dirección postal: Av. Libertador Bernardo O’Higgins, 340, Facultad de Derecho. Correo electrónico: afermandois@fermandois.cl

2 Abogada Pontificia Universidad Católica de Chile. Magíster en Gestión Cultural, Universidad de Chile. Dirección postal: Nueva Tajamar 481, Torre Norte, Of. 708, Correo electrónico: tchubret@fermandois.cl
} 
lizados, paralelos a la famosa acción cautelar del artículo 20 de la Carta Fundamental. En este escenario, ¿qué actitud debe adoptar la Corte Suprema ante un recurso de protección -acción cautelar de rango constitucional- interpuesto como vía sustitutiva, complementaria o simplemente alternativa a estas otras acciones? ¿A qué criterios deben atender los litigantes para decidir la sede donde plantear sus inquietudes?

En materia medioambiental, que en 2010 estrenó una nueva y moderna institucionalidad en Chile, la Corte Suprema ha sido en ocasiones vacilante. Aun desde la creación de los Tribunales Ambientales -que vinieron a coronar el trabajo de la Superintendencia del Medio Ambiente y el Comité de Ministros en materia de reclamación- al conocer de recursos de protección que invocan el derecho a vivir en un medio ambiente libre de contaminación (artículo $19 \mathrm{n}^{\circ} 8$ de la Constitución), no ha asentado un criterio unívoco para determinar cuándo procede esta acción cautelar y cuándo debe discutirse el asunto en sede especializada.

Se hace necesario entonces proponer una dogmática más clara en la materia, que ubique un punto de compatibilidad entre el siempre necesario e irrenunciable recurso de protección, de rango constitucional, y las reclamaciones deducidas al amparo de la ley $\mathrm{N}^{\circ}$ 20.600, de 2012, ante los tribunales del medio ambiente, sin desatender las potestades cautelares de la Superintendencia del ramo.

Este trabajo resulta motivado por recientes sentencias de la Corte Suprema que, aunque puedan ser inobjetables en su resultado, no permiten deducir una teoría consistente sobre la pertinencia o impertinencia procesal del recurso de protección en tópicos de medio ambiente. Así, no resulta fácil hacer una estimación de previsibilidad en uno y otro caso. Considerando la proliferación de conflictos recaídos en proyectos que impactan aspectos ambientales, urge más claridad doctrinaria que atribuya un sitio preciso, predecible, armónico y procesalmente prolijo para el recurso de protección en esta zona del derecho.

Este trabajo se propone identificar ese lugar en el marco de la nueva institucionalidad sectorial, sugiriendo una dogmática acerca de su convivencia con los nuevos órganos y sus procedimientos. Todo ello a partir, por una parte, del análisis sistemático de los pronunciamientos de la Corte Suprema en la materia, y por otro, de una interpretación sobre los alcances de la naturaleza de urgencia cautelar propia del recurso de protección.

\section{DIAGNÓSTICO EN 2015: DENSIFICACIÓN CRECIENTE DEL CONTROL JURISDICCIONAL SOBRE EL ESTADO Y PRESIONES SOBRE EL RECURSO DE PROTECCIÓN}

La primera tarea para abordar esta cuestión consiste en recorrer el escenario en que se enmarca la práctica constitucional y administrativa actual. Para ello, indagaremos sobre el sentido y valor del recurso de protección hoy en día, a fin de encuadrar lógica, jurídica y fácticamente el análisis posterior de su rol en materia medioambiental.

\section{A. Densificación CRECIENTE DEL CONTROL JURISDiCCIONAL ESPECIAL SOBRE EL ESTADO}

Una rápida mirada al contexto institucional permite constatar que se ha producido un progresivo aumento en la técnica de los tribunales especializados. Constituyendo una 
completa excepción hace solo una década ${ }^{3}$, hoy se van transformando en una regla sectorial casi normal, cada vez que existe una actividad con perfil propio en la vida económica, social o ciudadana.

Citemos algunos ejemplos: la creación del Tribunal de la Contratación Pública en 2003 (Ley N 19.886); del Tribunal de Defensa de la Libre Competencia en 2004 (Ley N ${ }^{\circ}$ 19.911 que sustituyó a la antigua Comisión Resolutiva Antimonopolios); de los Juzgados de Familia también en 2004 (Ley N 19.968); de los Juzgados de Letras del Trabajo y de cobranza laboral y previsional en 2005 (Ley $N^{\circ}$ 20.022); del Panel de Expertos en materia eléctrica en 2007 (DFL N 4 del Ministerio de Economía, Fomento y Turismo), de los Tribunales Tributarios y Aduaneros en 2009 (Ley N²0.322); del Consejo para la Transparencia también en 2009 (Ley $N^{\circ}$ 20.285); de los Tribunales Ambientales en 2012 (Ley $\mathrm{N}^{\circ}$ 20.600); así como de otros paneles y órganos especiales de conocimiento y muchas veces derechamente de resolución de controversias, como la Contraloría General de la República en juicio de cuentas, los alcaldes en recursos de ilegalidad municipal, etc.

En nuestra opinión, el aumento de jurisdicciones especializadas en Chile no es algo reprochable, sino beneficioso. Sometidas a la superintendencia de la Corte Suprema, materializan un principio que, al menos en materia económica, hemos promovido y denominado de la revisión judicial económica ${ }^{4}$. Sin perjuicio de lo deseable que resulta que el legislador dote de crecientes grados de independencia objetiva e imparcialidad subjetiva a estos jueces especializados - atributos propios del Poder Judicial- la tendencia es positiva. Los tribunales especiales aportan versación jurisdiccional en asuntos cada vez más complejos, en una sociedad que avanza en su desarrollo y genera relaciones internas que se van complejizando durante este tránsito. Los tribunales especializados promueven, en definitiva, el derecho constitucional a una tutela judicial efectiva, que en nuestra literatura se ha llamado derecho a la acción, ubicado en el artículo $19 \mathrm{~N}^{\circ} 3$ de la Carta Fundamental.

La Corte Suprema también ha respaldado, caso a caso, la creación de tribunales especializados. Con algunos matices ${ }^{5}$, el máximo tribunal ha despachado informes positivos frente a los últimos proyectos de ley que los crean, con ocasión del trámite exigido por el artículo 77 de la Constitución ${ }^{6}$.

\footnotetext{
3 Entre las cuales se cuentan las cuestiones de menor envergadura (juzgados de policía local), eleccionarias (tribunales electorales regionales y Tribunal Calificador de Elecciones) y de Propiedad Industrial (Tribunal de Propiedad Industrial).

${ }^{4}$ Fermandois (2006) p. 112.

5 Por ejemplo, en el caso de la ley que creó los Tribunales Tributarios y Aduaneros, hizo varias observaciones en orden a mantener la independencia de los jueces especiales: "la vía más idónea de fortalecer la jurisdicción tributaria consiste en estructurarla sobre la base de Juzgados Tributarios creados en el Poder Judicial, radicando en salas especializadas de las Cortes de Apelaciones el segundo grado del procedimiento y en la Corte Suprema la resolución de los recursos de casación correspondientes". Historia de la Ley $\mathrm{N}^{\circ} 20.322$, Biblioteca del Congreso Nacional, p. 438. Disponible en: <www.bcn.cl>

${ }^{6}$ En el caso de los Tribunales Ambientales, específicamente, la Corte Suprema en su informe celebró "como un aporte positivo la incorporación a nuestro sistema jurídico de un órgano jurisdiccional especializado en materias ambientales". Historia de la Ley $N^{\circ}$ 20.600, Biblioteca del Congreso Nacional, p. 42. Disponible en: $<w w w . b c n . c l>$
} 
Así, el recurso de protección debe hoy operar en un paisaje radicalmente diferente al existente cuando se creó en 1976. Hoy funciona en medio de numerosos tribunales unipersonales y colegiados, ubicados dentro o fuera del Poder Judicial, provistos de dotaciones e integraciones diversas pero unidos por un elemento común: su carácter intrínsecamente jurisdiccional, junto a la versación técnica (que se presume) de sus miembros.

\section{B. SubSisTENCIA DE JURISDiCCIONES ESPECIALIZADAS HistÓRICAS, JUDICIALES, MiXTAS O MERAMENTE ADMINISTRATIVAS \\ Pero nuestra acción cautelar no solo debe convivir con tribunales especializados de} carácter reciente; la Corte de Apelaciones, al conocerlo, está forzada también a armonizarlo con las sedes jurisdiccionales que históricamente han estado dotadas de competencia en materias especiales.

Aquí debe distinguirse entre los tribunales que se encuentran parcialmente fuera de la órbita de la Administración del Estado, como el Tribunal de Propiedad Industrial (que está sujeto a la superintendencia directiva, correccional y económica de la Corte Suprema, pero se aloja presupuestaria y administrativamente en el Ministerio de Economía), y las decenas de tribunales administrativos que ejercen jurisdicción, integrantes de la Administración bajo el artículo $1^{\circ}$, inciso segundo de la Ley $\mathrm{N}^{\circ}$ 18.575, de Bases Generales de la Administración del Estado.

Entre los muchos tribunales administrativos se ubican todos los Superintendentes, titulares de las 11 superintendencias que existen en el ordenamiento jurídico ${ }^{7}$. Todos ellos, con mayor o menor amplitud, están dotados de atribuciones fiscalizadoras y sancionadoras.

Se agregan una pléyade de órganos administrativos jurisdiccionales, como la DGA ${ }^{8}$, la DIRECTEMAR ${ }^{9}$, la DGAC ${ }^{10}$ y tantos otros que conocen asuntos técnicos, resuelven controversias a nivel administrativo o supuestamente administrativo, y sus sentencias son susceptibles de recursos ante la justicia ordinaria. Entre los tribunales históricos de tipo mixtos, se ubican órganos colegiados como la Corte de Mar, segunda instancia en los juicios marítimos sujetos a la ley respectiva ${ }^{11}$.

\footnotetext{
7 Superintendencia de Bancos e Instituciones Financieras (SBIF), Superintendencia de Seguridad Social (SUSESO), Superintendencia de Valores y Seguros (SVS), Superintendencia de Electricidad y Combustibles (SEC), Superintendencia de Servicios Sanitarios (SISS), Superintendencia de Salud, Superintendencia de Casinos de Juego (SCJ), Superintendencia de Pensiones (SP), Superintendencia del Medio Ambiente (SMA), Superintendencias de Educación Escolar, Superintendencia de Insolvencia y Reemprendimiento.

${ }^{8}$ El artículo 134 del Código de Aguas faculta a la Dirección General de Aguas para "dictar resolución fundada que dirima la cuestión sometida a su consideración”, refiriéndose a las controversias en procedimientos de adquisición o ejercicio de los derechos de aprovechamiento.

9 La Ley Orgánica de la Dirección General del Territorio Marítimo y de Marina Mercante (DFL Nº 292 de 1953), artículo 3 letra i) establece que "Corresponde a la Dirección: Dictaminar en los sumarios administrativos que se sustancien sobre accidentes y siniestros marítimos, determinar las responsabilidades que correspondan en ellos y aplicar sanciones".

${ }_{10}$ El artículo 184 del Código Aeronáutico faculta a la Dirección General de Aeronáutica Civil para "conocer y sancionar las infracciones de este código, de las leyes y reglamentos sobre aeronáutica y de las instrucciones que ella dicte en el ejercicio de sus atribuciones, salvo las que correspondan a la Junta de Aeronáutica Civil..."

${ }^{11}$ Decreto Ley 2.222 de 1978.
} 
El elemento común de estos tribunales es su alto componente administrativo: la presencia en ellos - unipersonal o colectivamente- de funcionarios de la Administración, que aportan precisamente el componente técnico y experiencia ejecutiva.

Podría afirmarse -y así lo han hecho la mayoría de los autores que reseñan su historia- que el recurso de protección nació para enmendar las posibles arbitrariedades o ilegalidades cuya fuente fuese el Estado y que comprometiesen derechos constitucionales. En esta zona institucional el recurso de protección tiene por definición una vocación de control democrático poderosa, más intensa que aquella cuyas controversias recaen en tribunales especializados.

Sin embargo, hoy, en 2015, la totalidad de las decisiones emanadas de tribunales administrativos $\mathrm{u}$ órganos administrativo-jurisdiccionales, son expresamente impugnables mediante recursos y acciones ante la justicia ordinaria. Así lo prevén sus leyes respectivas ${ }^{12}$, lo que matiza -aunque jamás elimina- la necesidad de intervención judicial extraordinaria.

\section{La ENTREga de ATRIBUCIONES JURISDiCCIONALES (SANCIONATORIAS) A ÓRGANOS TRADICIONALMENTE ADMINISTRATIVOS, RECONFIGURADOS Y CRECIENTEMENTE FORTALECIDOS}

Un tercer punto a considerar es esta tendencia legislativa creciente, que se encarna nítidamente, por ejemplo, en el Proyecto de Ley para fortalecimiento del SERNAC ${ }^{13}$.

El Mensaje referido - uno entre muchos análogos en los últimos años- busca potenciar la protección del consumidor mediante un órgano que norma, fiscaliza, conduce mediaciones y ahora pasará a sancionar infracciones, con clara identidad jurisdiccional. El

\footnotetext{
12 Por ejemplo, para los Tribunales Tributarios y Aduaneros (2010), los art. 120 y ss. del Código Tributario; para los Tribunales Ambientales (2012), el art. 26 de la Ley 20.600. Para el caso de las decisiones de las superintendencias: art. 22 Ley general de Bancos (1997) en el caso de la Superintendencia de Bancos e Instituciones Financieras (SBIF): art. 58 Ley 16.395 (1965), de la Superintendencia de Seguridad Social (SUSESO): art. 46 DL 3.538 (1980) de la Superintendencia de Valores y Seguros (SVS); art. 19 Ley 18.410 (1985) de la Superintendencia de Electricidad y Combustibles (SEC); art. 32 Ley 18.902 (1989) de la Superintendencia de Servicios Sanitarios (SISS): art. 7 Ley 18.933, a la cual remite el art. 23 de la Ley 19.937 (2004), de la Superintendencia de Salud; art. 34 Ley 19.995 (2005) de la Superintendencia de Casinos de Juego; art. 18 DFL 101/1980 Ministerio del Trabajo y Previsión Social, al cual remite el art. $47 \mathrm{~N}^{\circ} 10$ de la Ley 20.255 (2008) de la Superintendencia de Pensiones; art. 56 Ley 20.417 (2010) de la Superintendencia de Medio Ambiente (SMA); art. 85 Ley 20.529 (2011) de la Superintendencia de Educación; art. 341 de la Ley 20.720 (2014) de la Superintendencia de Insolvencia y Reemprendimiento (SIR, reemplaza a la Superintendencia de Quiebras). La mayoría de estas impugnaciones proceden ante las Cortes de Apelaciones directamente, salvo en el caso de la SMA, que se reclama ante el Tribunal Ambiental -y la SIR- que se reclama ante el juez de letras en lo civil; pero a su vez, las decisiones de estos dos tribunales son reclamables ante las Cortes de Apelaciones. Y en algunos de los ejemplos más recientes para otros órganos administrativos, encontramos el nombramiento por parte del Ministerio de Educación de un Administrador Provisional en instituciones de Educación Superior, que se puede reclamar ante la Corte de Apelaciones (art. 9 del proyecto promulgado con fecha 22 de diciembre de 2014) y el de las sanciones que pueda imponer el SERNAC conforme al proyecto de ley Boletín $N^{\circ}$ 9.369-03, reclamables ante el juez de letras en lo civil (nuevo art. $50 \mathrm{O}$ de la Ley $\mathrm{N}^{\circ}$ 19.496), entre muchos otros.

13 Proyecto de Ley que modifica la Ley $\mathrm{N}^{\circ}$ 19.496, sobre Protección de los Derechos de los Consumidores. Este proyecto se contiene en el Boletín del Congreso Nacional No 9.369-03, ingresado a la Cámara de Diputados mediante Mensaje de la Presidenta de la República N 141-362 de 2 de junio de 2014.
} 
nuevo SERNAC será esa clase de órgano multifuncional, al que no obstante se busca someter a control judicial mediante recursos ante el juez ordinario ${ }^{14}$.

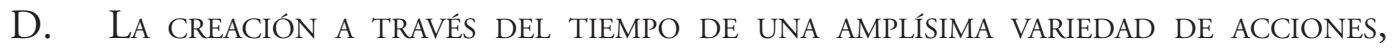
RECLAMACIONES, RECURSOS, AMPAROS Y TUTELAS JUDICIALES QUE SE FRANQUEAN A LA PERSONA AFECTADA POR UN AGRAVIO EN SUS DERECHOS

Esta también es una tendencia clara, irrefutable y positiva para nuestro Estado de Derecho. Así, encontramos en nuestro ordenamiento procedimientos como el amparo económico para cautelar el derecho del artículo $19 \mathrm{~N}^{\circ} 21$ (Ley $\mathrm{N}^{\circ} 18.971$ de 1990); el de tutela laboral ante los jueces de letras del trabajo para los derechos de los numerales 1, 4, 5, 6, 12 y 16 del artículo 19 CPR respecto a los trabajadores (Ley $N^{\circ} 20.087$ de 2005, artículo 485 del Código del Trabajo); la reclamación tributaria ante los Tribunales Tributarios y Aduaneros para los numerales 21, 22 y 24 del artículo 19 CPR (Ley No 20.322 de 2009, artículo 155 del Código Tributario), el reclamo ante el alcalde contra los actos ilegales del municipio (artículo 151 de la Ley $\mathrm{N}^{\circ} 18.695$ de 2006); el reclamo de ilegalidad de urbanismo y construcción ante la SEREMI del Ministerio de Vivienda y Urbanismo para la denegación de permisos de construcción (artículo 12 y 118 de la Ley General de Urbanismo y Construcción de 1975); las reclamaciones por conculcación de los derechos de los consumidores ante el SERNAC (Ley No 19.496 de 1997); los reclamos contra los prestadores institucionales de salud ante la Superintendencia de Salud (Ley No 20.584 de 2012); los reclamos contra las resoluciones de las superintendencias ante las Cortes de Apelaciones, de acuerdo a sus respectivas leyes (artículo 46 DL N 3.538 de 1980 para el caso de la Superintendencia de Valores y Seguros; artículo 85 Ley No 20.529 de 2011 para la Superintendencia de Educación; artículo 19 de la Ley Nº 18.410 de 1985 para la Superintendencia de Electricidad y Combustibles, artículo 22 del DFL Nº 3 de 1997 del Ministerio de Hacienda para la Superintendencia de Bancos, etc.); la reclamación contra los actos de la Subsecretaría de Telecomunicaciones (artículos 13 A, 15, 16, 36 A de la Ley $\mathrm{N}^{\circ} 18.168$ de 1982); contra los actos del Banco Central (artículo 69 Ley $\mathrm{N}^{\circ} 18.840$ de 1989); contra los actos del Consejo para la Transparencia (artículo 28 Ley N²0.285 de 2008); contra los actos de los gobiernos regionales (artículo 108 Ley $\mathrm{N}^{\circ} 19.175$ de 1992), y muchos otros.

En 1976, año de la dictación del Acta Constitucional N³, creadora del recurso de protección, el panorama era diametralmente opuesto. Las acciones judiciales disponibles para el ciudadano eran escasas, al margen de las tradicionales ordinarias del procedimiento civil y penal. La acción de reclamación de nacionalidad -de carácter político- el recurso de amparo penal y muy pocas adicionales configuraban el precario arsenal del ciudadano afectado en sus derechos, sobre todo cuando la afectación era generada por actos de la Administración. De hecho, el actual artículo 20 CPR nació ligado a la inquietud de algunos

\footnotetext{
14 Artículo primero numerales $20^{\circ}, 27^{\circ}$ y $35^{\circ}$ del proyecto, que incorporan los nuevos artículos 50 A), 50 N) y 50 0) y modifican el artículo 56 de la Ley $\mathrm{N}^{\circ} 19.496$, entregando competencias a los jueces de letras en lo civil para conocer de las indemnizaciones de perjuicios, reclamos de ilegalidad, así como de las denuncias interpuestas por el SERNAC en contra de proveedores, y a las Cortes de Apelaciones para resolver en segunda instancia.
} 
parlamentarios $^{15}$ de dotar a los particulares de una herramienta efectiva para resguardar sus derechos de propiedad, reunión y opinión, ante una sucesión de actos irregulares por parte del Poder Ejecutivo en el período 1970-1973 que no encontraban reparo por las vías existentes. Para ello solicitaron propuestas al Departamento de Derecho Público de la Universidad de Chile y a los profesores Navarrete y Soto Kloss de la Universidad Católica, siendo esta última presentada como moción de reforma constitucional en la legislatura extraordinaria 1972/73. Este mismo texto fue rescatado por el comisionado Evans, cuando al final de la sesión $N^{\circ} 213$ de la CENC se propuso discutir la "ampliación del recurso de amparo". En el debate de las sesiones celebradas entre el 20 y 27 de julio de 1976 quedó de nuevo plasmada la preocupación sobre el tratamiento procesal que los asuntos contenciosoadministrativos tenían a la fecha; así, la mayor motivación para fijar un medio constitucional fue la necesidad de resguardarse frente a decisiones de la autoridad ante la ausencia de vías eficaces ${ }^{16-17}$, aunque sin reemplazar la necesidad de dotar de mayor fuerza a los procedimientos ordinarios ${ }^{18,19}$.

Este escenario, como constatamos, ha experimentado un cambio radical entre 1976 y 2015, en cuanto al panorama de órganos, acciones y mecanismos dotados de tutela jurisdiccional sobre los actos del Estado y de los particulares que vulneren derechos constitucionales: mientras en el tiempo de promulgación del Acta Constitucional N³ la situación era frágil, hoy la cobertura de caminos jurisdiccionales conferidos al ciudadano es profusa, generosa. Esto último, sin embargo, no elimina ni podría eliminar la pertinencia del recurso

\footnotetext{
15 Onofre Jarpa, Diez, Arnello, Lorca y Undurraga.

16 De hecho, don Alejandro Silva se mostró contrario en un comienzo a la idea misma de crear un nuevo recurso que pudiera utilizarse en este ámbito, planteando en la Sesión N² 214 lo siguiente: "organizado debidamente lo contencioso-administrativo y reconocido como función propia de los tribunales la de resolver ellos mismos todo problema que surja de la vulneración o quebrantamiento de los derechos que la Constitución reconoce, el recurso propuesto pudiera no ser necesario". Sin embargo, luego de la aclaración del invitado ministro Lorca y del comisionado Evans, en el sentido de que el objetivo perseguido era diferente -proteger urgentemente un derecho sin perseguir sanción o reparación de la autoridad-, lo cual implicaba un procedimiento especial, sumarísimo, apoyó su implementación.

17 Véase Ferrada, et al. (2003) p. 69 y 77. Bordalí lo refuerza: "aún si pensamos que los jueces ordinarios eran competentes bajo la Carta de 1925 para conocer del contencioso-administrativo, la verdad es que el Código de Procedimiento Civil no contenía ninguna vía procesal adecuada para hacer frente con cierta urgencia a una violación de derechos. Solo estaban los interdictos posesorios o juicios sumarios que tutelaban exclusivamente el hecho de la posesión de bienes inmuebles. La alternativa habría sido utilizar el juicio ordinario y quizá intentar dentro de él una medida cautelar innominada que autoriza el artículo 298 CPC”. Bordalí (2006) p. 209.

18 Según el profesor Pierry, el reemplazo de un procedimiento especial "no puede haber estado en el ánimo de la Comisión de Estudio", la cual preveía que en el futuro "coexistirían una acción contencioso administrativa, contemplada en la respectiva ley, y un recurso de protección para determinadas situaciones". PIERRY (1977) p. 177-178.

19 Esto se constata también a la luz de la discusión en la CENC sobre la incorporación de la última frase del artículo 20 inciso primero, "sin perjuicio de los demás derechos que pueda hacer valer ante la autoridad o los tribunales correspondientes”. Según se desprende especialmente de la Sesión No 216, vino a responder a la inquietud por la interpretación que alguna jurisprudencia hacía de la procedencia del recurso de amparo, sosteniendo en definitiva que una vez deducido precluían las demás vías procesales. Fue para evitar esa situación -la preclusión de los demás medios de tutela jurídica- que consideraron los comisionados necesario dejar constancia expresa de su vigencia; no se pretendió, entonces, erigir al recurso de protección simplemente como el único medio de protección, sino como una vía extraordinaria, de urgencia, ante esas otras ordinarias.
} 
de protección en cualquier materia, la que de todas formas resulta suavizada, disminuida en su necesidad otrora apremiante.

\section{E. El IMPERATIVO DE MANTENER y PROTEGER LA FLEXIBILIDAD, POTENCIA PROCESAL Y JERARQUÍA CONSTITUCIONAL DEL RECURSO DE PROTECCIÓN}

Este breve recuento de antecedentes pareciera llevarnos a una conclusión evidente: que el recurso de protección debiese ir perdiendo relevancia, que debiese ir cediendo espacios ante la avalancha de jueces y procedimientos más modernos, más precisos y más accesibles en el ordenamiento.

Pero esa sería una conclusión apresurada. Es primordial preservar la vitalidad institucional del recurso de protección, su trascendental rol de garantía de derechos constitucionales, evitando privarlo de eficacia, aún en un ordenamiento jurídico como el de hoy, plagado de instancias especializadas de control judicial. Ello, incluso habiéndose satisfecho luego de casi 40 años, el objetivo del constituyente de 1976.

En efecto, deteriorar el recurso de protección sería una regresión, un retroceso del que nadie podría estar orgulloso. Se trata de un acierto indiscutible y de unánime respaldo de la Carta Fundamental.

Por ello, hemos de buscarle al recurso un espacio lógico, armónico con la institucionalidad de 2015, para una convivencia pacífica y eficiente con la infinidad de jueces y acciones sectoriales que la ley ha conferido a los ciudadanos.

\section{F. Ausencia de una dogmática Clara Que ARMonice adeCUadamente la Convivencia del Recurso de Protección con las JuRisdicciones especiales,} SU ÁMBITO Y LÍMITE, Y HAGA PREVISIBLE SUS ALCANCES Y RESULTADOS

Es patente la dificultad de la academia, de la Administración y de la opinión profesional especializada para entender los criterios que explican el acogimiento de los recursos de protección en algunos casos y su desechamiento en otros, existiendo procedimientos especiales. Y en especial, se ha venido haciendo complejo comprender debidamente los criterios de la Corte sobre protecciones promovidas en paralelo al procedimiento ambiental y su acto administrativo terminal, la Resolución de Calificación Ambiental (RCA).

En efecto, como recuerda Galindo Villarroel, así como las cortes rechazaron durante años las protecciones ambientales con el argumento que llamaremos de la "inavocabilidad técnica", hoy esta es una causal de exclusión acogida esporádicamente en ciertas ocasiones ${ }^{20}$ y desechada en otras ${ }^{21}$, sin que pueda intuirse con precisión las reglas que la regirían. Igual cosa puede decirse de la causal identificada como "urgencia cautelar". Propia del recurso de protección desde sus inicios, aparece usada para rechazar numerosos recursos ambientales por no estimarse por los sentenciadores existir tal urgencia. En otras ocasiones, empero, aún sin visibles males inminentes en el expediente, los tribunales superiores omiten el criterio de la urgencia cautelar y acogen el recurso. ¿Qué debemos entender por urgencia

\footnotetext{
20 Desde el emblemático caso Trillium (1997) a otros reconocimientos expresos como el caso Costa Laguna (2014) y otros indirectos como el caso Curtiembre Rufino Melero (2014).

${ }^{21}$ Como en el caso Central Castilla (2012).
} 
cautelar? ¿Cuáles son los parámetros fácticos e institucionales de inminencia que convocan a la Corte a actuar vía protección, por sobre las demás acciones disponibles ante tribunales especiales?

Igual cosa podríamos decir de muchos otros elementos de exclusión, y principalísimamente de la que hemos llamado "deferencia institucional", usada alternativamente para rechazar el recurso o ignorada para admitirlo.

Es lo que ocurre también con el argumento de los "derechos indubitados", tradicionalmente indispensables para ocurrir a la Corte de protección, pero que se transforma en un eje de imprevisibilidad en los resultados del recurso, por la ausencia de parámetros básicos sobre qué debemos entender por "indubitados".

Así, existe una percepción de jurisprudencia aparentemente vacilante y hasta contradictoria en las cortes superiores de justicia al resolver recursos, admitiendo en algunos casos un control constitucional intenso en materias técnico-ambientales, y negándolo en otros.

A continuación queremos, entonces, explorar un balance, un punto de equilibrio entre el deseo del constituyente de franquear al ciudadano -con máximo rango jurídicouna acción de tutela de sus derechos fundamentales, y el respeto al rol que el legislador y el Administrador han venido construyendo con tribunales especializados e institucionalidades administrativas sectoriales, esenciales para el funcionamiento de una sociedad cada vez más demandante y compleja, especialmente en cuestiones ambientales.

\section{LA PROCEDENCIA DEL RECURSO DE PROTECCIÓN EN MATERIA AMBIENTAL}

Frente a este diagnóstico, los criterios históricos de exclusión del control constitucional requieren una segunda mirada. Sobre todo en asuntos contencioso-administrativos, donde la doctrina desde hace casi dos décadas viene denunciando "...la transformación del Recurso de Protección en un medio de impugnación ordinario de la actuación administrativa (...) en un mecanismo de control de la legalidad o juridicidad de la actuación administrativa, afectando con ello la urgencia, excepcionalidad y esencialidad de su tutela" 22 .

Uno de estos casos es el de los conflictos ambientales. ¿Qué espacio institucional le cabe al recurso de protección en esta materia? ¿Cómo y cuándo corresponde que una Corte de Apelaciones conozca, falle y acoja un recurso de protección que, directa o indirectamente, se encamine a dejar sin efecto actos administrativos que contienen permisos ambientales? ¿Cómo debe entenderse lo anterior a partir de la dictación de la Ley $N^{\circ}$ 20.417, que crea el Ministerio del Medio Ambiente, el Servicio de Evaluación Ambiental (SEA) y la Superintendencia del Medio Ambiente (SMA), y, especialmente, de la Ley No 20.600, fuente de los Tribunales Ambientales?

A continuación, indagaremos en otros criterios que se desprenden de los propios pronunciamientos de la Corte Suprema para acotar este fenómeno. Un análisis sistemático de los últimos fallos más importantes en la temática nos aportará parámetros y estándares generales sobre la procedencia de la acción constitucional.

22 Ferrada et al. (2003) p. 68. 


\subsection{Criterios jurisprudenciales para la procedencia o EXClusión del ReCURSO de PROTECCIÓN EN MATERIA AMBIENTAL}

Además de los criterios que derivan inmediatamente del texto del art. 20 CPR, la jurisprudencia ha delineado estándares para definir cómo y cuándo procede el recurso de protección respecto al derecho a vivir en un medio ambiente libre de contaminación. Para ello, ha replicado los argumentos sobre la convivencia de la acción con otros procedimientos especiales, especificando su aplicación en esta materia desde la operación de la nueva institucionalidad ambiental.

\section{a. Primer criterio de exclusión. Deferencia institucional o existencia de una jurisdicción y procedimientos ambientales especiales}

El primer criterio de discernimiento esgrimido en la jurisprudencia acerca de la idoneidad del recurso de protección ante problemáticas ambientales ha sido la existencia de nuevos órganos especializados.

Según la Corte Suprema, la existencia de estos órganos es la justificación basal de una nueva posición para discernir: "no obstante establecerse (...) que la interposición del recurso de protección lo es sin perjuicio de los demás derechos que puedan hacerse valer ante la autoridad o los tribunales competentes (...) a contar de la dictación de la Ley (...) que crea los tribunales ambientales, son estos los llamados a conocer de las controversias medioambientales" 23 .

En efecto, podríamos decir que a partir del año 2012, todos los pronunciamientos se construyen desde esa premisa: el carácter específico del ramo, su orgánica y procedimientos. Así lo reconocen también las Cortes de Apelaciones, como las de Santiago ${ }^{24-25}$, Valparaíso ${ }^{26}$ y Puerto Montt ${ }^{27}$.

Ahora bien, como lo hemos afirmado reiteradamente, la sola existencia de esta institucionalidad y procedimientos no anula la competencia de la justicia constitucional. En efecto, el criterio orgánico necesariamente debe ser complementado con otros. Sin embargo, desde ya constatamos que este criterio siempre está presente y es aceptado unánimemente por las Cortes, y opera en forma independiente de las demás distinciones.

Así sucedió, por ejemplo, en el conocido caso de El Morro, donde finalmente la Corte Suprema acogió los recursos razonando, sin embargo, que "no puede perderse de vista que a contar de la dictación de la Ley (...) que crea los tribunales ambientales, son estos los llamados a conocer de las controversias medioambientales que se encuentren sometidas a su competencia, dentro de las cuales se encuentra por cierto la solicitud de invalidación

\footnotetext{
23 Corporación Fiscalía del Medio Ambiente contra Servicio de Evaluación Ambiental Región de Aysén (2012), considerando $4^{\circ}$ (caso Río Cuervo).

24 Solis Olguin Gladys y otros con Servicio de Evaluación Ambiental (2013), considerando $4^{\circ}$.

25 Ximena Cazorla Cazorla y otros contra Dirección Ejecutiva del Servicio de Evaluación Ambiental (2014).

${ }^{26}$ Junta de Vecinos JJ.VV. Norte contra Comisión de Evaluación Ambiental V Región (2013), considerando $4^{\circ}$.

27 Leopoldo David Muñoz de la Parra y otros contra Resolución Exenta $N^{\circ} 128$ de la Comisión de Evaluación de la $X$ Región de los Lagos y otros (2014).
} 
de una Resolución de Calificación Ambiental..." ${ }^{28}$. Fue en razón de otros criterios que la Corte estimó que el recurso debía parcialmente prosperar; pero los sentenciadores no dejaron pasar la oportunidad de hacer constar la preferencia de la jurisdicción especial por sobre la protección.

En definitiva, la jurisprudencia es elocuente al considerar que cuando existe una competencia y procedimiento específico para impugnar acciones u omisiones que afecten el derecho a vivir en un medio ambiente libre de contaminación, esa competencia y procedimiento no pueden simplemente ser descartados, suplantados o desatendidos por el recurso que nos ocupa ${ }^{29}$.

Tenemos, entonces, un criterio orgánico de exclusión nítido, asentado en la Corte: la deferencia institucional.

Mas, como se dijo, no es un criterio único. Si así lo fuese, no habría prosperado ningún recurso de protección desde la Ley $\mathrm{N}^{\circ}$ 20.600, y ese no ha sido el caso.

\section{b. Segundo criterio de exclusión. Inavocabilidad técnica: No cabe revisar el mérito técnico del recurso de protección}

El segundo criterio de discernimiento desarrollado por la jurisprudencia en sede de recurso de protección, deriva del criterio clásico de los derechos indubitados, que permitió durante muchos años a la Corte denegar protecciones. Se trata ahora de algo menos jurídico y más material: lo llamaremos inavocabilidad técnica. Consiste en sustraer a la Corte del conocimiento de recursos de protección que exijan evaluar, revisar o calificar el mérito técnico de decisiones adoptadas por la Administración.

Pero, ¿en qué consiste lo técnico y hasta dónde se extiende? No es sencilla esta respuesta, especialmente considerando que el artículo 20 del Código Supremo autoriza a reparar vía protección cualquier ilegalidad en materia ambiental, sin excluir las técnicas, y siempre que sea imputable a una persona determinada.

Nos parece que la inavocabilidad técnica es un criterio valioso en la relación CorteTribunales especializados, pero no resulta suficiente por sí sola; no resuelve todos los problemas ni es capaz de generar un conjunto de reglas satisfactoriamente predecibles. Entre otras razones, porque habrá casos en que el vicio alegado será de carácter efectivamente técnico - por ejemplo cuando se trata de la determinación de líneas de base ambientales o de áreas de influencia de los proyectos- pero el caso tendrá otras características que harán a la Corte intervenir de todas formas acogiendo el recurso y amparando derechos constitucionales amagados, aun moviéndose en plenos dominios de la técnica.

28 Comunidad indígena diaguita Yastai de Juntas de Valeriano y otros contra Comisión de Evaluación Ambiental (CEA) (2014), considerando $8^{\circ}$. El considerando $9^{\circ}$ enfatiza: "si los reclamantes han pedido que esta Corte invalide una Resolución de Calificación Ambiental dictada por la autoridad técnica competente aduciendo que adolece de vicios de legalidad en su otorgamiento, tal pretensión, por sus características, debe ser resuelta en sede de la nueva institucionalidad a que se ha aludido, pues ella constituye la sede natural en que asuntos de esta naturaleza deben ser conocidos, salvo que se vislumbre la necesidad de adoptar alguna medida cautelar de carácter urgente". Sobre este otro criterio (que llamaremos "urgencia cautelar") nos explayaremos más adelante.

29 Véase al respecto Pinilla (2014). Concordamos con dicho autor que la no utilización oportuna de las vías pertinentes, además, es un razonable indicio de ausencia de urgencia cautelar, según veremos más adelante. 
¿Cuáles son esas otras características? Intentaremos proponerlas en el próximo apartado. Por ahora, detengámonos en la jurisprudencia reciente sobre el mérito técnico como causal de exclusión del recurso de protección, que ha tenido aplicación en otros procedimientos sectoriales ${ }^{30}$, pero ha encontrado su mayor desarrollo en conflictos ambientales.

Galindo Villarroel recuerda que, en la materia, este criterio es de antigua data. Debutó en el famoso caso "Trillium" 31 en 1998, en que la primera sala de la Corte Suprema (y no la Tercera, por vigencia del antiguo Auto Acordado), afirmó que "no forma parte de su estudio el pronunciarse sobre las bondades técnicas que presenta un proyecto, que ha sido sometido a la autoridad competente" 32 . En aquella época no existían tribunales especializados, y lo técnico era terreno de la Administración.

La vigencia de la inavocabilidad técnica para descartar la protección se extiende entonces casi por dos décadas en sentencias de las cortes. Se aplicó recientemente, con motivo de la construcción de la Línea 3 del Metro de Santiago, donde en sentencia de 9 de septiembre de 2013, en rol N 40.665-2012, la Corte de Apelaciones de Santiago observó en su considerando $6^{\circ}$ que "se ha empleado el presente arbitrio procesal para poner en entredicho la legalidad de una decisión técnica, pretensión que excede los márgenes de esta acción constitucional...”. En aquel caso, los recurrentes solicitaron algo usual en reclamos vía protección: que se exigiera a Metro S.A. el ingreso al Sistema de Evaluación de Impacto Ambiental (SEIA) a través de un Estudio de Impacto Ambiental (EIA) y no de una Declaración de Impacto Ambiental (DIA).

La Corte Suprema aplicó nuevamente la inavocabilidad técnica en el ya citado caso Costa Laguna añadiendo algunas consideraciones: “...determinar si es procedente uno u otro mecanismo de evaluación ambiental... corresponde a una cuestión en extremo compleja que, por regla general, va a exceder el ámbito propio de esta acción constitucional... exige apreciar proyectos o actividades sobre la base de evaluaciones técnicas, labor que en principio resulta ajena a este procedimiento cautelar" ${ }^{\prime 3}$.

En el mismo sentido se pronunció en el caso Sierra Gorda sobre el análisis que tendría que haber realizado para ponderar si la organización y distribución de cargas y descargas y servicios portuarios considerados aisladamente, influían en el carácter legal o ilegal de

\footnotetext{
30 Un ejemplo reciente es la sentencia Inmobiliaria Torre Barón II S.A. contra Dirección de Obras de la Ilustre Municipalidad de Valparaíso (2013). Ahí, si bien se acepta la procedencia del recurso contra la Dirección de Obras de la Municipalidad de Valparaíso por negar una solicitud de Aprobación de Anteproyecto respecto de predios ubicados en la comuna, se desestima el fondo en base a lo siguiente (considerando $21^{\circ}$ ): “Que así expuesta la controversia, fluye naturalmente que tal materia excede - pero con mucho-, el ámbito del recurso de protección, en cuanto procedimiento de urgencia que es, en la medida que su objetivo, conforme literalmente establece el artículo 20 de la Carta Fundamental, es que la Corte de Apelaciones adopte "de inmediato las providencias que juzgue necesarias para restablecer el imperio del derecho y asegurar la debida protección del afectado", lo que aquí evidentemente no ocurre, menos con los antecedentes proporcionados, cuando se encuentran en discusión aspectos eminentemente técnicos”.

31 Girardi Lavin, Guido y otros Comisión de Evaluación Ambiental (1998).

32 Galindo (2003) p. 152.

33 Junta de Vecinos JJ.VV. Norte contra Comisión de Evaluación Ambiental V Región (2014), considerando $6^{\circ}$.
} 
las declaraciones de impacto ambiental. Dijo que “...en suma, se trataría de aspectos técnicos que no es posible tratarlos en este recurso..."34.

De manera que el contenido de esta causal de exclusión es claro según las sentencias recientes: no le correspondería a la Corte, en un recurso cautelar extraordinario, hacerse cargo del "entredicho técnico" de las resoluciones del SEA.

Sin embargo, el criterio de la inavocabilidad técnica requiere una construcción dogmática adicional que lo complemente. Así lo hizo la Corte, por ejemplo, en el caso Sierra Gorda, donde tomó en cuenta también i) que "existe un procedimiento previamente establecido y muy pormenorizado", según ya vimos, y ii) que "la acción cautelar requiere de derechos indubitados e inequívocos que ostenten los titulares de la acción para disponer el restablecimiento de los derechos o asegurar la debida protección a los afectados" ${ }^{35}$.

Por último, obsérvese una reciente sentencia de la Corte Suprema, que falló una protección interpuesta contra una curtiembre en la Región del Maule que estaba generando olores molestos a la comunidad vecina. En el recurso, los afectados pidieron la suspensión de las actividades de la curtiembre y el ingreso de la misma al SEIA, además de las otras providencias que la Corte estimare necesarias. En primera instancia, la Corte de Apelaciones de Talca acogió el recurso. No obstante, no resolvió sobre el cese de actividades de la curtiembre ni su ingreso al SEIA, sino que se limitó a ordenarle "adecuar su actividad para evitar que olores molestos o malos olores sean expedidos de la industria, por cualquier medio, e impedir que alcancen a ser percibidos por los vecinos, debiendo abstenerse de toda operación que produzca efectos contrarios a ello", para lo cual debía "permanecer fiscalizada por la Superintendencia del Medio Ambiente, quien deberá informar a esta Corte cada seis meses" 36 . Este fallo fue confirmado por la Corte Suprema con fecha 26 de noviembre de 2014, pero con efectos aún más limitados: en su decisión eliminó la obligación impuesta a la SMA de informar a la Corte de Apelaciones. Así, el fallo demuestra una combinación entre inavocabilidad técnica y deferencia institucional, profesada hacia la nueva institucionalidad ambiental. Aunque se acogió aquí el recurso, ambos trasuntan un rechazo a medidas amplias de restablecimiento del imperio del derecho concebidas fuera de los órganos especializados.

\section{c. Criterio bidireccional. La cautela urgente}

Quizá el filtro más impredecible y flexible que adoptan las cortes para acoger o denegar recursos de protección en terreno ambiental, es el que llamaremos de la cautela urgente. La doctrina coincide unánimemente en que la protección efectivamente es una acción cautelar destinada a otorgar un remedio inmediato y urgente a un derecho constitucional comprometido por una ilegalidad (o arbitrariedad en los derechos no ambientales). Ello,

34 Lema Keith Guillermo Patricio con Mardones Lara Dalia Ester (2014), considerando $13^{\circ}$.

35 Lema Keith Guillermo Patricio con Mardones Lara Dalia Ester (2014), considerando $13^{\circ}$.

36 Luis Roberto Arévalo Parra, Miriam Santelices Valenzuela, Ana Cáceres Soto, María Valenzuela Guerrero y otros con Curtiembre Rufino Melero S.A también (Curtiembre) rep Javier Melero Urrestarazu y José Enrique León Rodriguez (2014). 
sin perjuicio de los demás derechos y acciones que puedan hacerse valer (art. 20, inciso primero CPR).

El asunto es identificar algún indicio sobre qué debemos entender por situaciones que ameriten esta clase de reacción cautelar urgente. No es sencillo identificar patrones sobre un asunto que sospechamos casi enteramente fáctico y casuístico.

La Corte de Apelaciones de Valparaíso ha definido la cautela urgente como la necesidad de "reaccionar contra una situación de acto anormal que de manera evidente vulnere una garantía constitucional", en oposición a la de "resolver conflictos relacionados con la interpretación de una norma legal" ${ }^{37}$. Este es el concepto más recurrido por la jurisprudencia, existan o no recursos especiales para reparar el asunto.

Entre las protecciones ambientales más notorias de los últimos años en las que la Corte Suprema ha utilizado el criterio de la cautela urgente, en uno u otro sentido, se encuentran el Caso Hidroaysén ${ }^{38}$ (sentencia de 4 de abril de 2012, rol N ${ }^{0}$ 10.220-2011, considerando $9^{\circ}$ ), el Caso Sierra Gorda ${ }^{39}$ (sentencia de 26 de febrero de 2014, rol № 1837 2013, considerando $8^{\circ}$ ), el Caso Río Cuervo ${ }^{40}$ (sentencia de 21 de agosto de 2014, rol $\mathrm{N}^{\circ}$ 2.463-2012, considerando $5^{\circ}$ ), el Caso El Morro ${ }^{41}$ (sentencia de 7 de octubre de 2014, rol $\mathrm{N}^{\circ}$ 11.299-2014, considerando $11^{\circ}$ ), el Caso Bocamina $\mathrm{II}^{42}$ (sentencia de 6 de noviembre de 2014 , rol $\mathrm{N}^{\circ} 15.737-2014$, considerando $12^{\circ}$ y $24^{\circ}$ ).

De lo esgrimido en estos fallos podemos extraer tres conclusiones sobre el concepto de cautela urgente en materia ambiental. Primero, que el criterio de la cautela urgente como situación que detona la intervención de la Corte vía recurso de protección, se debilita si el recurrente no recurre en forma inmediata contra los actos del procedimiento ambiental y espera hasta su término (Hidroaysén). Segundo, que ilegalidad no es sinónimo de cautela urgente; esta última tiende a oponerse al de simple ilegalidad, la que debe ventilarse ante los órganos de la institucionalidad ambiental (Río Cuervo) o al menos exige un análisis adicional (El Morro). Y tercero, que el criterio de la cautela urgente autoriza a la Corte

\footnotetext{
37 Junta de Vecinos JJ.VV. Norte contra Comisión de Evaluación Ambiental V Región (2013), considerando $3^{\circ}$.

38 “...ello va en contra del plazo establecido para impetrar medidas de cautela y además porque deja en evidencia la falta de urgencia en la necesidad de protección si se esperó que el procedimiento llegase a su fin para impugnar los actos anteriores, máxime cuando de ello dependía el curso que se iba a dar al proceso..."

39 "el recurso de protección preventivo se genera a propósito justamente de indicios de estar inminente algo malo o desagradable, como define la Real Academia Española al concepto de amenaza..."

40 “...si los recurrentes han pedido que esta Corte invalide una resolución de calificación ambiental (...) aduciendo que adolece de vicios de legalidad en su otorgamiento, tal pretensión, por sus características, debe ser resuelta en sede de la nueva institucionalidad (...), tanto más si no se vislumbra en el presente caso quebrantamiento alguno de un derecho que haya de restablecerse de manera urgente mediante la acción cautelar intentada (...)”.

41 “... cabe analizar si las ilegalidades denunciadas en el recurso de protección por los apelantes requieren de una cautela urgente e inmediata a las garantías constitucionales que denuncian como infringidas con el objeto de otorgar una protección urgente a las mismas".

42 "Conviene reiterar que la presente acción constituye una medida de tutela urgente de modo que, si en el curso de su substanciación se detectan riesgos o amenazas graves en relación a las garantías antes aludidas cuyo acaecimiento sea verosímil, corresponderá adoptar las medidas que se estimen conducentes para otorgar la debida protección"... "Que lo anteriormente asentado justifica que esta Corte adopte las medidas de cautela indispensables para la protección impetrada, entre tanto se sustancia y decide, por las vías correspondientes (...) el conflicto integral que afecta a la Central Termoeléctrica Bocamina”.
} 
a intervenir ante indicios certeros de riesgos o amenazas (Sierra Gorda), que como tales deben ser graves; esto es, la magistratura debe acudir ante presagios de males inminentes y muy relevantes, que no pueden consistir en riesgos ordinarios (Bocamina II).

\subsection{Los nuevos criterios para una Teoría General de la Protección Ambiental. CARÁCTER EXTRAORDINARIO DEL RECURSO}

Hasta aquí, hemos sostenido que aun con lo plausibles que resultan, los tres criterios clásicos de exclusión usados por las cortes para discernir sobre cuándo atender o cuándo desechar un recurso de protección en materia medioambiental son insuficientes.

Por eso, ahora propondremos otros tres criterios adicionales para completar el análisis. Y junto a ello ofreceremos parámetros adicionales para mensurar mejor el de la urgencia cautelar ya citada. Con esto aspiramos a agregar a este sensible juicio jurisdiccional grados crecientes de consistencia, previsibilidad y lógica para jueces, funcionarios administrativos y titulares de los derechos constitucionales.

Hagamos de inmediato una advertencia: el concepto que subyace a la procedencia del recurso de protección es lo extraordinario, lo grave, lo excepcional. Se trata de amparar a un titular de derechos subjetivos públicos que aparece gravemente ofendido por un acto. En este concepto justificante de la protección no hay duda alguna; no hay novedad, hay completa unanimidad doctrinaria.

Lo extraordinario es, por lo pronto, propio del derecho comparado para todas las acciones de tutela de rango constitucional.

En el caso de España, ya el mismo nombre de su famosa acción constitucional símil del recurso de protección chileno, el amparo extraordinario, es indicativo de su naturaleza excepcional. El interesado debe necesariamente recurrir previamente a la sede judicial ordinaria (que sería la "posta de primeros auxilios"43) antes de deducir el amparo constitucional. Así se consagra legalmente en los artículos $43^{44}$ y $44^{45}$ de la Ley Orgánica del Tribunal Constitucional, y dicha Magistratura ha insistido que "la jurisdicción de amparo es subsidiaria de la jurisdicción común y no es una instancia directa, ni tampoco revisora, porque el restablecimiento del derecho primariamente debe tratarse de conseguir ante los

\footnotetext{
43 Palomo (2007) p. 417.

44 "Las violaciones de los derechos y libertades antes referidos originadas por disposiciones, actos jurídicos, omisiones o simple vía de hecho del Gobierno o de sus autoridades o funcionarios, o de los órganos ejecutivos colegiados de las comunidades autónomas o de sus autoridades o funcionarios o agentes, podrán dar lugar al recurso de amparo una vez que se haya agotado la vía judicial procedente".

45 "Las violaciones de los derechos y libertades susceptibles de amparo constitucional, que tuvieran su origen inmediato y directo en un acto u omisión de un órgano judicial, podrán dar lugar a este recurso siempre que se cumplan los requisitos siguientes:

a) Que se hayan agotado todos los medios de impugnación previstos por las normas procesales para el caso concreto dentro de la vía judicial.

b) Que la violación del derecho o libertad sea imputable de modo inmediato y directo a una acción u omisión del órgano judicial con independencia de los hechos que dieron lugar al proceso en que aquellas se produjeron, acerca de los que, en ningún caso, entrará a conocer el Tribunal Constitucional.

c) Que se haya denunciado formalmente en el proceso, si hubo oportunidad, la vulneración del derecho constitucional tan pronto como, una vez conocida, hubiera lugar para ello".
} 
tribunales ordinarios, empleando todos los medios de impugnación normales existentes en las normas procesales, y solo cuando fracasen se puede abrir el proceso de amparo..."46.

La literatura insiste en que el amparo extraordinario no transforma al Tribunal Constitucional español en una tercera instancia, conforme al principio de subsidiariedad procesal que lo rige. Por consiguiente, no cabe utilizarlo para cuestiones de mera legalidad, y su decisión debe emanar de la propia Constitución ${ }^{47}$. Además, debe haber un daño material significativo ${ }^{48}$, y debe tener "relevancia constitucional" ${ }^{49}$; así lo ha ido definiendo jurisprudencialmente, aunque esto último, al igual que la subsidiariedad, fue objeto de una reforma legal para restringir normativamente su utilización abusiva ${ }^{50}$.

Tal como en el caso chileno, el recurso de amparo fue recuperado en el ordenamiento español en un contexto de desconfianza hacia el juez ordinario como "único baluarte de los derechos y libertades" 51 . Marc Carrillo justifica esta desconfianza ciudadana, entre otras razones, en declaraciones como la contenida en el Auto 35/1980 del Tribunal Supremo, donde sostuvo que el principio de igualdad y el derecho a no ser discriminado (artículo 14 de la Constitución española) era solo un "principio programático". Ante circunstancias como esa, afirman los autores, el recurso de amparo constituía la única vía efectiva para hacerlos valer. Pero, hoy en día, la generalidad de la doctrina española comparte que la sede natural o habitual de su garantía son los juzgados y tribunales ordinarios, a través de un "modo de enjuiciamiento", que permita "ahondar en todos los vericuetos formales y materiales que identifican el caso" 52 . Esto sería especialmente válido, dicen, respecto de los actos del Poder Ejecutivo, considerando el perfeccionamiento de la jurisdicción contenciosoadministrativa en España con la incorporación del procedimiento preferente y sumario en la Ley del ramo en $1998^{53}$.

En Alemania la situación es similar. La subsidiariedad de la justicia constitucional también está prevista expresamente desde 1985 en el artículo 90, apartado 2, párrafo 2 de la Ley del Tribunal Constitucional Federal, con requisitos semejantes al caso español, asignándole a dicha magistratura la función de "decidir de inmediato sobre un recurso de amparo interpuesto antes del agotamiento de la vía jurídica, cuando el recurso sea de in-

\footnotetext{
46 STC N¹06/1980 y 60/1981. En Palomo (2007). p. 402. En el mismo sentido, STC No 151/1999, en Montoro (2003) p. 236.

47 Acuerdo Tribunal Constitucional Español N 63/1980: "la competencia del Tribunal Constitucional deriva de la Constitución y solo de ella o, eventualmente, en normas de ella derivadas, puede fundamentar sus decisiones"; y $\mathrm{N}^{\circ}$ 145/1983: "la competencia del Tribunal Constitucional no es omnímoda, ya que está referida a las violaciones de la Constitución española y en el recurso de amparo a las relativas a los artículos (...) y que no se trata de una jurisdicción que juzgue de la legalidad, misión específicamente otorgada a la jurisdicción de los tribunales ordinarios". Montoro (2003), p. 239-240.

48 Palomo (2003) p. 434.

49 A partir de la modificación del año 2007 a la Ley Orgánica 2/1979, del Tribunal Constitucional.

50 Palomo (2003) p. 442. En el mismo sentido, Carrillo (2008) p. 89.

51 Carrillo (2008) p. 94.

52 Carrillo (2008) p. 97.

53 Palomo (2003) p. 456.
} 
terés general o, cuando, de no hacerlo así, se le irrogase al recurrente un perjuicio grave o inevitable" 54 .

Fernández Segado afirma respecto a este amparo o queja constitucional alemán, el "Verfassungsbeschwerde": el recurso de queja no es un recurso adicional, esto es, un instrumento procesal adicional a los existentes ante los jueces y tribunales ordinarios con vistas a recabar la tutela de un derecho supuestamente trasgredido; por el contrario, se trata de un recurso extraordinario..." 55 .

El amparo constitucional entonces, en los casos más paradigmáticos del derecho comparado, no es el camino usual de tutela judicial: debe exhibir y acreditar un estándar elevado de gravedad y excepcionalidad. Ello tanto en la infracción misma, como en la magnitud de la afectación y la trascendencia del asunto, todo en un contexto de su subsidiariedad respecto a la justicia ordinaria.

Centrémonos ahora en el caso del recurso de protección chileno, a fin de proponer criterios adicionales para identificar esta excepcionalidad en las causas que deben conocerse por vía del recurso de protección, aún en zonas de competencia propia de tribunales especiales.

\section{a. Primer criterio. Rango normativo del ilícito: reserva legal estricta y no reglamentaria}

Si sabemos que el recurso de protección existe para reparar una afectación extraordinaria, lo primero que debe exigirse al recurrente, para ser consistente con ello, es una reserva legal estricta a la hora de fundar la ilegalidad de su recurso.

Conocemos que la ilegalidad es -a diferencia de los demás derechos que admiten arbitrariedad- el único eje de todo recurso de protección que invoque el medio ambiente. Así, atendido que el recurso de protección procede respecto del numeral $8^{\circ}$ de la Carta, solo cuando esta garantía sea afectada "por un acto u omisión ilegal" (artículo 20, inciso segundo), el recurrente deberá necesariamente imputar una infracción de ley a una autoridad o persona determinada.

Luego, ¿qué debe entenderse por ley para efectos del recurso de protección?

Proponemos que la ilegalidad debe consistir en una vulneración de una norma de rango estrictamente legal y no reglamentario. Esto es, que el ilícito al que se sindica como origen de la vulneración del derecho al medio ambiente descontaminado esté primariamente contenido y definido en una ley, en un cuerpo normativo emanado del procedimiento constitucional de formación de la ley (arts. 65 y siguientes de la Carta Fundamental). No resultaría compatible con el carácter extraordinario del recurso, ni con la existencia de una jurisdicción medioambiental especializada omitida, el que la ilegalidad promovida vía protección se haga consistir en una infracción de un ilícito propio y autónomo de un reglamento, ni mucho menos, una infracción de una norma administrativa infrarreglamentaria, como las instrucciones de la SMA y los instructivos del SEA.

54 Carrillo (2007) p. 319.

55 Fernández (2008). Véase también Morales (2010) p. 322. 
Naturalmente, los decretos y reglamentos complementan las leyes, "desarrollan, detallan y llevan adelante las disposiciones legislativas" ${ }^{56}$, en lenguaje de Bertelsen. La potestad reglamentaria, de acuerdo al Tribunal Constitucional, sirve para "hacer así posible el mandato legal", "pormenorizando y particularizando, en los aspectos instrumentales, la norma" ${ }^{57}$ (que debe ser "detallada" y "específica" ${ }^{58}$ ). Por regla general la norma administrativa estará conectada con la ley, materializará sus mandatos, y será la ley la fuente de la regulación cuya infracción detonará la ilegalidad. Tan intenso es este elemento que en la doctrina se ha sostenido que "no hay tipicidad sin legalidad"59.

Ahora, esa conexión entre el precepto reglamentario y la ley debe ser estrecha, próxima, propia al menos de un estándar de reserva legal poderosa ${ }^{60-61}$, en contraposición a la técnica de la reserva legal relativa, es decir aquella en que las normas reglamentarias se alejan de la ley, disponen con grados amplios de autonomía de la ley, o en otros casos con absoluta independencia de lo previsto en ella.

En estos casos, cuando en realidad no es la ley la que dispone una regulación sino el reglamento lo está haciendo por su propia cuenta, no podría jamás fundarse en ello una "ilegalidad" idónea para que prospere un recurso de protección. No sería este proceder coherente con una interpretación de la voz constitucional "ilegal" en el inciso segundo del artículo 20 de la Carta, ni consistente con la voluntad constitucional de que el ilícito salve un umbral mínimo de gravedad y de excepcionalidad ${ }^{62}$.

Por el contrario, esta clase de infracciones parecen propias de un tribunal ambiental. Como podrá apreciarse breves párrafos más adelante, las regulaciones administrativas autónomas de la ley son bastante comunes en el Derecho del Medio Ambiente; de ahí la necesidad de usar este elemento interpretativo a la hora de juzgar una protección.

El elemento clave para este análisis es atender a la esencia de la obligación o prohibición que se imputa infringida. Sus elementos esenciales, ¿están en la Ley $\mathrm{N}^{\circ} 19.300$ ? ¿O solo en los reglamentos que la complementan?

La exigencia estricta de ley para el recurso de protección, y no de norma jurídica en sentido amplio, tiene además coherencia con la relevancia de la intervención del ciudadano en la definición de la obligación que se alegará vulnerada ante la Corte. Se trata de un umbral democrático: es el ciudadano representado democráticamente en el Congreso mediante sus parlamentarios, en un procedimiento público, colectivo, el que define sus principales

\footnotetext{
56 Bertelsen Repetto, Raúl, en Fermandois (2006) p. 162.

57 Requerimiento respecto del Decreto Supremo No 20 del Ministerio Secretaría General de la Presidencia publicado en el Diario Oficial de 12 de abril de 2001 ( $r o l N^{\circ} 325$ ), considerando $41^{\circ}$.

58 Requerimiento respecto del Decreto Supremo No 20 del Ministerio Secretaría General de la Presidencia publicado en el Diario Oficial de 12 de abril de 2001 ( $r o l N^{\circ} 325$ ), considerando $40^{\circ}$.

59 VAN WeZel (2011) p. 161. Si bien esta afirmación es más intensa tratándose de la determinación de delitos o infracciones, también aplica para los deberes cuyo incumplimiento detonan sanciones. Así, dice el autor, se desprende del considerando $20^{\circ}$ de la sentencia de 27 de junio de 2006, rol $\mathrm{N}^{\circ} 480$, del Tribunal Constitucional (p. 164-165).

${ }^{60}$ Véase Fermandois (2006) pp. 162 y 163.

61 Véase Fermandois (2001) p. 313.

${ }^{62}$ Un desarrollo extenso de los temas de legalidad que justificarían la exclusión del recurso de protección se encuentra en Gómez (2015), p. 117 y siguientes.
} 
preocupaciones, aquellas cuya desatención por la autoridad administrativa ameritan reclamarse en una acción extraordinaria y no en una simple acción ante los tribunales del ramo.

\section{b. Segundo criterio. Densidad Típica del ilícito}

Un segundo elemento dogmático lógico, indispensable de exigir a un recurrente que prefiere una acción constitucional extraordinaria y desecha los tribunales especializados del medio ambiente, es precisión en su imputación. Para esto, la ilegalidad que enarbola el actor debe estar además descrita con alta precisión en la ley; no le cabe al objetor invocar figuras genéricas, insuficientemente construidas. En suma, debe existir densidad normativa en el ilícito que detonaría la entrada de la Corte, esa entrada que conceptualmente desplazará al juez especializado que sin embargo no fue convocado a la controversia.

Como señaló el Tribunal Constitucional en su famoso fallo Impacto Vial (2003), por "densidad normativa" debemos entender que el legislador, además de "establecer, crear o instituir una obligación", debe especificar "sus aspectos y elementos definitorios o característicos, trazando, con adecuada densidad normativa, en qué consiste el deber que impone, cuál es el motivo de función social que lo justifica, cuáles son sus delimitaciones, sobre la base de qué supuestos fácticos se torna procedente exigirla, cuál es la autoridad competente para llevarla a efecto y controlarla, a quiénes y por qué motivos se les exime de ella, etc.”63. La ley debe determinar con precisión en qué consiste la obligación, cuándo debe cumplirse, quién está obligado a servirla, a favor de quién cede, etcétera. Y esa ley así configurada con detalle, una vez lesionada por un acto u omisión, detona plausiblemente una protección.

En síntesis, bajo este criterio no cabe recurrir de protección invocando obligaciones genéricas vulneradas, mandatos vagos, que no significan parámetros de sujetos obligados, contenidos materiales o definiciones cronológicas sobre cómo debe cumplirse la obligación insatisfecha. Si así no fuera, desaparecería en el recurso de protección su naturaleza intrínsecamente cautelar ante un ilícito patente, nítido y evidente, todos atributos indiscutidos de esta acción.

En la misma Ley $N^{\circ} 19.300$ sobre Bases Generales del Medio Ambiente podemos encontrar ejemplos de suficiencia (o insuficiencia) típica, que ayudan a comprender este criterio.

Un primer ejemplo de obligación genérica lo encontramos en torno a los mecanismos de participación ciudadana, donde dispone el artículo 26 de la Ley $\mathrm{N}^{\circ} 19.300$ que estos "serán establecidos por las Comisiones de Evaluación o el Director Ejecutivo". Se aprecia ahí una obligación precisa en el imperativo de establecerlas, pero genérica respecto del cómo deben estructurarse. No es esta parte un mandato preciso a las Comisiones de Evaluación Ambiental o al Director Ejecutivo del SEA: su amplitud permite utilizar diferentes instrumentos, lo que se entiende bajo la lógica de la diversidad de comunidades y proyectos.

También es genérica la obligación del SEA de abrir nuevas etapas de participación ciudadana cuando hay aclaraciones, rectificaciones o ampliaciones "sustantivas" recogidas

63 Requerimiento de inconstitucionalidad presentado por doce señores Senadores respecto del Decreto Supremo No 1 , del Ministerio de Vivienda y Urbanismo, publicado en el Diario Oficial de 1 de febrero de 2003 ( $\mathrm{rol} \mathrm{N}{ }^{\circ} 370$ ). 
en los procesos iniciales de participación (Art. 29). En la ley nada se dice de qué se entiende por "modificación sustantiva": solo se vino a detallar en el nuevo Reglamento del SEIA, el año 2012.

Esta técnica legislativa de precisión y generalidad simultánea en ciertas obligaciones se aprecia en varios pasajes de la Ley $\mathrm{N}^{\circ} 19.300$. Por ejemplo, respecto de la obligación del SEA de considerar las observaciones en el proceso de evaluación ambiental, una parte es precisa: "deberá hacerse cargo de estas, pronunciándose fundadamente de todas ellas en su resolución”. Es decir, el SEA está obligado a pronunciarse de todas las observaciones recogidas: esa es una obligación legal precisa cuya infracción podría ser controlada en una protección. Pero es de inevitable generalidad la obligación de que lo haga "fundadamente", la cual, pese a toda la doctrina sobre la motivación de los actos administrativos, exige un complemento reglamentario y técnico que es más propio del Tribunal Ambiental.

Añade la ley que, sin perjuicio de la falta de precisión, las personas cuyas observaciones no hubieren sido "debidamente consideradas en los fundamentos de la RCA" podrán presentar recurso de reclamación ante el Comité de Ministros. ¿Qué se entiende por "debida consideración"?

Bajo estos preceptos legales, la Corte no puede resolver la satisfacción de sus obligaciones atendiendo al simple texto de la ley. Precisamente por su carácter técnico, le es dificultoso al Tribunal de Alzada calificar qué debe entenderse por aclaraciones, rectificaciones o ampliaciones "sustantivas"; lo mismo respecto de que se entiende por "fundadamente", o la "debida consideración".

Otra obligación que cuenta con una densidad típica mixta, es la de ingresar un proyecto al SEIA. El artículo 10 de la Ley N 19.300 tiene una extensa lista de proyectos y actividades que deben someterse al SEIA. En tanto, aquella parte de la obligación que distingue sobre si el ingreso deba hacerse vía EIA o DIA, no es tan evidente en su tipificación. En efecto, las circunstancias que motivarían un EIA están previstos en la ley en forma abierta en el artículo 11 y no es simple determinarlos ex-ante; deben ellos necesariamente complementarse con el reglamento del SEIA.

De esta manera, el Recurso de Protección solo tiene aquí un lugar constitucional armónico -respecto de estas obligaciones- cuando el órgano administrativo hubiere dejado de cumplir aquella parte de la obligación que exhibe suficiencia típica en la misma ley.

Así, respecto de la obligación que le cabe al Director Ejecutivo o a las Comisiones de Evaluación de "establecer los mecanismos que aseguren la participación informada de la comunidad en el proceso de calificación", si ella se ha omitido del todo, esto es, si la autoridad ha faltado a este mandato y se emite una RCA sin haberse aplicado estos mecanismos, naturalmente un recurso de protección podría amparar al afectado. En igual situación nos encontraremos si un proyecto o actividad de los identificados en el artículo 10 de la Ley $\mathrm{N}^{\circ}$ 19.300 derechamente no ingresa al SEIA.

Pero la sede judicial apta para discutir la suficiencia de la participación ciudadana o los efectos de la actividad o proyecto es naturalmente el Tribunal Ambiental, precisamente porque la ilegalidad no se basta a sí misma en la Ley $\mathrm{N}^{\circ} 19.300$. 
Por el contrario, si la obligación se encuentra en la misma ley claramente tipificada, exhibiendo suficiente precisión en sujetos y objeto, entonces el recurso de protección tiene las puertas abiertas bajo este criterio que proponemos.

Es el caso de la obligación del artículo 27 de la Ley $N^{\circ} 19.300$, que dispone que "cualquier persona, natural o jurídica, podrá imponerse del contenido del proyecto y del tenor de los documentos acompañados": si el recurrente alegare y probare que le fue negado el acceso al contenido del proyecto o a los documentos, entonces se habrá infringido una obligación legal nítidamente identificable, apta como ilegalidad para un recurso de protección. En este caso, además, esa obligación representa un bien jurídico de alta valoración: el principio de bilateralidad, propio del debido proceso del artículo $19 \mathrm{~N}^{\circ} 3$ de la Carta Fundamental.

Lo mismo sucede con la obligación de publicación del artículo 28, claramente determinada en la Ley.

También son precisas las normas sobre la caducidad de la RCA (artículo 25 ter Ley $N^{\circ} 19.300$, incluido a través la Ley $N^{\circ}$ 20.417): si alguien iniciase un proyecto o actividad luego de 5 años de otorgada, sería ello manifiestamente ilegal, en una infracción típicamente suficiente e intensa.

También lo es la obligación de que todo proyecto o actividad evaluada en el SEIA debe contar con la opinión de la autoridad territorial general (artículo $8^{\circ}$ inciso $3^{\circ}$ Ley $\mathrm{N}^{\circ}$ 19.300), autoridad que es determinada en la misma ley. Si no existe pronunciamiento de esta, habría ilegalidad suficiente para sede de protección; lo mismo si se omite el deber de publicación, o si se pretende ejecutar un proyecto una vez caducada la RCA.

\section{c. Tercer criterio. Alto rango valorativo del ilícito}

Un tercer elemento indispensable de exigir al recurrente de protección, coherente con su naturaleza extraordinaria, es la especial valoración del bien jurídico ultrajado por la acción u omisión que se denuncia. El rango jurídico del mandato legal vulnerado no puede ser el ordinario, no puede ser el común: debe ubicarse entre los bienes jurídicos apreciados por la sociedad y por el legislador.

Este elemento, irrefutable conceptualmente, es, no obstante, complejo de someter a parámetros. Debe reconocerse que puede aparecer en principio excesivamente indefinido y hasta vago. Pero en realidad, tal como se verifica en el desarrollo jurisprudencial y académico del principio preventivo ${ }^{64}$, se encuentran perfectamente al alcance ciertos indicios que revelan una valoración especial al bien jurídico que se estima infringido. Desde el punto de vista del derecho constitucional, proponemos los siguientes:

i. Si la obligación infringida, dotada de densidad normativa suficiente, se ubica en la misma Constitución.

Este es un primer indicio obvio de valoración: de conformidad al artículo $6^{\circ}$ de la Constitución, esta es suprema. Sus preceptos obligan tanto a los titulares e integrantes de los órganos del Estado, "como a toda persona, institución o grupo". Luego, todo mandato u obligación que se encuentre en la Carta Fundamental, exhibe la máxima valoración nor-

64 Véase por ejemplo Urrutia (2013) p. 492. 
mativa disponible en el ordenamiento jurídico y en principio, podría bastar para fundar una ilegalidad propia de un recurso de protección.

Ahora, sabemos que normalmente los mandatos constitucionales son genéricos, y por lo tanto no satisfacen aquel otro elemento que propusimos previamente en este Informe, el de la densidad típica propia de la "ilegalidad". Con todo, por excepción podrían esos mandatos ser precisos y ubicarse en la misma Ley Suprema. Por ejemplo, en otra materia, el mandato del artículo 40 de la Carta Fundamental, que está dotado de un plazo: "la declaración de estado de sitio solo podrá hacerse por un plazo de 15 días”. En este caso, la obligación tiene alta valoración por encontrarse en la Ley Suprema, pero además dispone de precisión típica, de un plazo; no es una vaguedad y podría servir de ilegalidad, en el sentido de una protección.

ii. Si la obligación infringida se ubica dentro de los principios fundantes de un determinado cuerpo legal, código o subsistema regulatorio.

Debemos conceder que existen ciertos principios que, sin encontrarse en la Constitución, cumplen el rol de piedras angulares de legislación sectorial. Por ejemplo, para la Ley $\mathrm{N}^{\circ} 19.300$, los principios y obligaciones de los artículos $3^{\circ}$ y $4^{\circ}$ de la ley (reparación del daño, participación ciudadana, acceso a la información), exhiben ese carácter. En consecuencia, la Corte en recurso de protección podría legítimamente abocarse a restablecer el imperio del derecho si se reclama como ilegalidad la vulneración de estos bienes jurídicos altamente valorados, siempre que otros preceptos de rango legal completen suficientemente la tipicidad de las obligaciones que imponen, como ya comentamos.

En síntesis, todo recurso de protección, como acción cautelar extraordinaria, debe invocar y justificar valorativamente por qué el asunto debe conocerlo y repararlo la Corte y no el Tribunal Ambiental; debe, en suma, denunciar y probar que la acción u omisión es antijurídica y que representa un verdadero quebranto del orden jurídico. En la jerarquía de los bienes tutelados en el Estado de Derecho, su clamor no podrá jamás ser la corrección de una minucia reglamentaria que no represente, en rigor, una infracción conceptual o materialmente grave.

\section{d. Cuarto criterio. La urgencia cautelar}

Uno de los criterios históricamente más asociados al carácter extraordinario del recurso de protección, es el de la cautela urgente. Decíamos que se trata de un criterio bidireccional, porque de faltar este, el recurso debe ser rechazado sin más, y de existir, la Corte está obligada constitucionalmente a reparar el imperio del derecho, siempre que la ilegalidad vulnere derechos protegidos.

La urgencia, entonces, es desde sus orígenes la causa justificante de la creación del recurso, de su rango constitucional y de la jerarquía del tribunal que conoce. Así se plasmó en la sesión $\mathrm{N}^{\circ} 214$ de la CENC, donde el Presidente Enrique Ortúzar expresó que el recurso de protección "es un procedimiento de emergencia, por decirlo así, que tiene por objeto lisa y llanamente, mientras se discute ante la justicia ordinaria en forma lata el problema planteado, restablecer el imperio del derecho que ha sido afectado". En el mismo sentido el profesor Soto Kloss observa: "el agravio, en general, ha de ser notorio, o mani- 
fiesto, o bien perceptible, de un modo fácil sin profundas disquisiciones teóricas o sesudas investigaciones o complejas pruebas" ${ }^{65}$.

Pero decíamos también que el desafío que se levanta hoy en 2015, es proveer e identificar algún parámetro, algún indicio sobre qué debemos entender por situaciones que ameriten esta reacción cautelar urgente en materia medioambiental. La cautela urgente tiende a percibirse como un filtro impredecible y flexible, por lo que resulta muy oportuno ofrecer nuevos parámetros que satisfagan la demanda por certidumbre en torno al deber de cautela.

Para ello recurriremos a ciertos criterios objetivos, a lecciones jurisprudenciales y a razones de lógica y justicia.

i. Nuevas y amplias potestades cautelares de la SMA y de los Tribunales Ambientales

Un primer elemento a considerar para determinar el rol de resguardo que corresponde a la Corte hoy en temas ambientales, es la vigorización cautelar de la institucionalidad ambiental.

La Ley $\mathrm{N}^{\circ}$ 20.417, de 2010, cambió radicalmente el paisaje jurídico-cautelar en materia de medio ambiente. Al crearse la SMA, se facultó en el artículo 48 de su ley orgánica al Superintendente para decretar un total de seis medidas cautelares cuyo objeto es precisamente prevenir daños o males inminentes al entorno. Tres de esas medidas pueden ser solicitadas por el instructor del proceso por daño medioambiental y decretadas directamente por el Superintendente; otras tres requieren ser autorizadas por el Tribunal Ambiental. Pero, en cualquier caso, la operación de las medidas cautelares es expedita.

Asimismo, desde el año 2012, en los procedimientos judiciales llevados ante los Tribunales Ambientales estos pueden decretar medidas cautelares, conservativas o innovativas para prevenir o mitigar los efectos negativos de los actos o conductas sometidos a su conocimiento. Conforme al artículo 24 de la Ley $\mathrm{N}^{\circ} 20.600$ pueden ser solicitadas en cualquier estado del procedimiento, e incluso antes de su inicio, fijándolas el tribunal por el plazo que estime conveniente. Puede decretarlas de plano y, siempre que existiere motivo grave, podrá disponer que se lleven a efecto antes de notificar a la persona contra quien se dictan.

En ambos casos, quienes solicitan las medidas están facultados para insistir en su otorgamiento: de la resolución de la Superintendencia que deniegue una medida cautelar solicitada en conformidad al artículo 48 de la Ley $\mathrm{N}^{\circ} 20.417$, se puede reclamar ante el Tribunal Ambiental (art. 56 Ley N²0.417), y si este también la rechazare, se puede recurrir de reposición y luego acudir a la Corte de Apelaciones a través del recurso de queja (art. 47 Ley $N^{\circ}$ 20.600, que remite al Código de Procedimiento Civil). Asimismo, de las medidas cautelares solicitadas al Tribunal de acuerdo al artículo 24 de la Ley $N^{\circ}$ 20.600, procede reposición y luego queja ante la Corte.

En consecuencia, la necesidad institucional de acudir con un amparo urgente por parte del Estado para una persona amenazada gravemente de daño a sus derechos del medio ambiente ha sido especialmente satisfecha por vías administrativas y judiciales ordinarias distintas del recurso de protección: los mismos efectos se pueden obtener por dichas

65 Soto Kloss (1982) p. 215. 
vías $^{66}$. Además, debe tenerse en cuenta que la independencia del órgano que conoce del reclamo también ha quedado satisfactoriamente lograda, al ser el Tribunal Ambiental el órgano competente para conocer, decretar y renovar las más importantes de estas medidas.

En este contexto, el Recurso de Protección no puede tener otro espacio -en cuanto al criterio de la urgencia cautelar- que cubrir aquellos eventos graves y muy excepcionales en que, por alguna causa, les haya sido imposible a los afectados impetrar las medidas administrativas y judiciales del artículo 48 de la ley $\mathrm{N}^{\circ} 20.417$ o del artículo 24 de la Ley $\mathrm{N}^{\circ}$ 20.600. Por el contrario, pugna con su naturaleza constitucional excepcional, que el recurso de protección se use para revisar, cuestionar o impugnar lo resuelto previamente por el Superintendente o por el Tribunal del Medio Ambiente en materia de medidas cautelares, en sustitución o suplantación de las vías ordinarias de impugnación procesal.

\section{ii. Jurisprudencia: intensificación de las exigencias}

La jurisprudencia posterior a la Ley No 20.417 confirma, en grandes rasgos, que el umbral de la urgencia cautelar se elevó considerablemente si ha de ser acogido en un recurso de protección: ante la existencia de medios adecuados, solo una urgencia acreditada permite prosperar ante la Corte de Apelaciones.

En efecto, un análisis detenido del caso Curtiembre Rufino Melero permite verificarlo: la Corte acogió el recurso ordenando al recurrido adecuar su actividad para evitar los malos olores y abstenerse de las operaciones que los produzcan -que sería en este caso, lo urgente, comprobados los malos olores por una serie de documentos técnicos proporcionados dentro de la fiscalización ambiental- y expresamente direcciona a la fiscalización de la SMA, sin pronunciarse sobre las peticiones propiamente ambientales del recurso (el ingreso al SEIA). Es decir, solo considera la urgencia en razón de comprobaciones de las autoridades pertinentes en el marco de sus fiscalizaciones, y solo ordena las medidas estrictamente necesarias enmarcadas en el derecho a la vida y a la salud de los vecinos.

Lo mismo se había dispuesto en Bocamina II: sustentados técnicamente por las autoridades pertinentes los problemas, acoge el recurso por considerar necesario terminar con las emisiones y las deficiencias en la succión de agua de mar, pero tomando solo las "medidas indispensables" y remitiendo el "conflicto integral" a la nueva institucionalidad.

Los casos Línea de transmisión Loncoche-Villarrica ${ }^{67}$, Central Hidroeléctrica Pangui $^{68}$, Piscicultura Caburga ${ }^{69}$, Línea de transmisión Melipeuco-Freire también han recalcado este imperativo rechazando los recursos interpuestos, aduciendo razones tales como que "en la especie, no se ha explicitado ningún impacto concreto a las comunidades aledañas que pueda generar este proyecto" 70 . De esta forma, la exigencia de explicitar razonablemen-

\footnotetext{
66 Acerca de los efectos del recurso de protección en materia ambiental, véase BERMúdez (2014) p. 145.

${ }^{67}$ Comunidad Indígena Felipe Nitribuala contra Comisión Regional del Medio Ambiente, Región de la Araucanía (2011).

68 Comunidad Indígena Juan de Dios Ancamil III contra Comisión Evaluadora Ambiental (2013)

69 Comunidad Indigena Mariano Millahual y otras contra Comisión Evaluadora Ambiental Región de la Araucanía (2014).

${ }^{70}$ Asociación Indígena Tragún Mapu Maile Allipen contra Comisión Evaluadora Ambiental, Región de la Araucanía (2012).
} 
te los argumentos técnicos de afectación de derechos ha sido un elemento gravitante en casi todos los fallos de los últimos años ${ }^{71}$.

Finalmente, citamos otro reciente fallo de la Corte Suprema, donde, habiéndose previamente decretado medidas cautelares por la Superintendencia -la paralización del funcionamiento del proyecto, aprobada por el Tribunal Ambiental- extendidas en tres ocasiones $^{72}$, la Corte rechaza el recurso remitiendo a la institucionalidad ambiental. Argumenta que dicha pretensión "por sus características (...) se enmarca dentro de las facultades que por ley se le han conferido a la Superintendencia del Medio Ambiente, institución que efectuó... una inspección ambiental respecto del incumplimiento denunciado por los actores... por lo que no es posible vislumbrar en el presente caso el quebrantamiento de un derecho que haya de restablecerse mediante la acción de protección cautelar urgente que ha sido intentada"73.

Es ahí, entonces, en el actuar de la Superintendencia, donde se verifica el necesario resguardo de los derechos de los recurrentes y no existiendo antecedentes de la insuficiencia de las medidas cautelares o documentos técnicos que exijan adoptar otras providencias, no se cumple con el estándar que justifica el uso de la vía extraordinaria.

\section{CONCLUSIONES}

El recurso de protección está asociado a la excepcionalidad en materia ambiental. A contar de la nueva institucionalidad del ramo emanada de las leyes 20.417 de 2010 y 20.600 de 2012, el Recurso de Protección solo puede resultar admisible ante eventos graves y muy excepcionales en que, por alguna causa, no se haya podido resguardar los derechos constitucionales mediante las vías de reclamación sectoriales. La creación de los tribunales ambientales, dotados de competencia jurisdiccional y cautelar en la materia, alteraron especialmente en esta zona del derecho, si bien en absoluto eliminaron, los estándares de procedencia de un recurso de protección sobre actos administrativos propios del procedimiento ambiental.

El análisis de la jurisprudencia da cuenta que existen tres criterios tradicionales para identificar la gravedad y excepcionalidad intrínseca del recurso: la inavocabilidad técnica, la deferencia institucional y la cautela urgente. Estos tres criterios tradicionales son correctos y, en el caso de los recursos de protección, son además determinantes para sugerir el rechazo de un recurso de protección que aparece, en este proceso, usado en paralelo de la institucionalidad ambiental y sus tribunales especializados. Empero, pese a ser muy acertados, hemos concluido que los criterios jurisprudenciales clásicos pueden resultar $-\mathrm{y}$ han

\footnotetext{
${ }^{71}$ Más aún si se trata de actos-trámite previos a la RCA - respecto de la cual ya existe consenso en que se trata de un acto terminal- la acreditación de la afectación debe ser concreta y plausible. Pero incluso en estos actos intermedios, si se acreditare daño y no hubieren otros medios cautelares suficientes, podrían ellos ser dejados sin efecto vía acción recurso de protección. Al respecto, véase Leppe (2013).

72 Disponible en: <http://www.sma.gob.cl/index.php/noticias/comunicados/483-sma-extiende-clausura-delautodromo-de-codegua-hasta-fin-de-ano>

73 George Winston Rivers Matamala y otros contra Inversiones Estancilla S.A., representante legal Pedro Miguel Ortiz Cuevas (2014), considerando $8^{\circ}$.
} 
resultado- insuficientes para resolver toda la casuística que generan los proyectos sometidos a autorización ambiental, con adecuados grados de previsibilidad y sistematicidad.

Ante ello, hemos propuesto tres criterios adicionales para identificar con mayor precisión cuándo la ilegalidad para cuyo amparo se interpone un recurso de protección en materia de medio ambiente, alcanza el umbral suficiente de gravedad y excepcionalidad que amerita la intervención de la Corte, restableciendo esta el imperio del derecho en reemplazo de los tribunales ambientales.

Los tres nuevos criterios consisten en la densidad típica; la reserva legal estricta y el rango valorativo del ilícito. El primero exige que la norma cuya infracción se alega en sede de protección contenga una descripción suficientemente densa y no genérica; el segundo criterio sugiere que la ilegalidad que se promueve ante la Corte, para alcanzar el nivel de gravedad en protección que desplace a los tribunales especializados, debe constar efectiva e íntegramente en una norma de rango legal y no en reglamentos o normas infralegales; y el tercer criterio exige que el bien jurídico invocado al recurrir de protección, tenga alta valoración jurídica, lo que sucede cuando se encuentra recogido en la Constitución o en las piedras angulares de un subsistema regulatorio legal.

Además, hemos propuesto que el criterio clásico de la urgencia cautelar, intrínseca del recurso de protección desde sus inicios, se haga prudencialmente más exigente luego de haber entrado en vigencia las poderosas atribuciones cautelares de la SMA y de los Tribunales Ambientales. Así, proponemos que un recurso de protección solo pueda prosperar, bajo este criterio, cuando, satisfechos los demás parámetros, el recurrente pruebe técnicamente el daño o amenaza y que le haya sido imposible y por causas que no le son imputables, solicitar a su turno medidas cautelares ante las sedes administrativa y judicial especializadas.

La aplicación de estos parámetros permitirá probablemente identificar mejor cuándo un recurso de protección -cuya petición consiste en dejar sin efecto el acuerdo de la Comisión de Evaluación Ambiental que antecede a la emisión de una RCA- alcanza el grado de gravedad suficiente para prosperar en los tribunales superiores de justicia por esta vía cautelar constitucional.

\section{BIBLIOGRAFÍA CITADA}

Bermúdez Soto, Jorge (2014): Fundamentos de Derecho Ambiental (Valparaíso, Ediciones Universitarias de Valparaíso, segunda edición).

Bordalí Salamanca, Andrés (2006): "El recurso de protección entre exigencias de urgencia y seguridad jurídica, Revista de Derecho, vol. XIX, N², diciembre 2006.

Carrasco Quiroga, Edesio (2011): “Corte Suprema, Consulta Indígena y Sistema de Evaluación de Impacto Ambiental: Una relación que no termina de aclararse”, Sentencias Destacadas 2010. Una mirada desde las políticas públicas. (Santiago, Ediciones LyD).

Carrillo López, Marc (2007): "Jurisprudencia constitucional y tribunales ordinarios", en 50 años de Corte Constitucional italiana, 25 años de Tribunal Constitucional español I coord. por Miguel Revenga Sánchez, Emilio J. Pajares Montolío, Juan Ramón Rodríguez-Drincourt Alvarez. 
Carrillo López, Marc (2008): "La objetivación del recurso de amparo: una necesidad ineludible", Revista Vasca de Administración Pública Nº 81.

Fermandois Vöhringer, Arturo (2001): "La ausencia de control del mérito por el Tribunal Constitucional: un objetable legado del caso catalíticos”, XXII Revista de Derecho de la Universidad Católica de Valparaíso.

Fermandois Vöhringer, Arturo (2006): Derecho Constitucional Económico: Garantías Económicas, Doctrina y Jurisprudencia, Tomo I (Santiago, Edición Universidad Católica, segunda edición).

Fernández Segado, Francisco (2008): "El control de las omisiones legislativas por el Bundesverfassungsgericht”, UNED. Teoría y Realidad Constitucional, N²2.

Ferrada Bórquez, Juan Carlos et al. (2003): "El recurso de protección como mecanismo de control jurisdiccional ordinario de los actos administrativos: una respuesta inapropiada a un problema jurídico complejo", Revista de Derecho, Vol. XIV.

Ferrada Bórquez, Juan Carlos y Bordalí Salamanca, Andrés (2008): "El derecho fundamental a la tutela judicial del ciudadano frente a la Administración del Estado", Revista de derecho administrativo: doctrina, legislación, jurisprudencia, $\mathrm{N}^{\circ} 2$.

Ferreira Mendes, Gilmar (2008): "La jurisdicción constitucional en Brasil: las relaciones entre el Supremo Tribunal Federal y los demás jueces y tribunales", Revista Derecho del Estado, N $\mathrm{N}^{\circ} 21$.

Fiamma Olivares, Gustavo (1986): "La acción constitucional de nulidad: un supremo aporte del constituyente de 1980 al derecho procesal administrativo", Revista de Derecho Pontificia Universidad Católica de Valparaíso, $\mathrm{N}^{\circ} 10$.

Galindo Villarroel, Mario (2003): "El caso Itata: sobre el control jurisdiccional de la discrecionalidad técnica a través del recurso de protección”, Revista de Derecho Ambiental, vol. I.

Gómez Bernales, Gastón (2015): "Jurisprudencia Medioambiental: ¿decisionismo o racionalidad pública?”, Sentencias Destacadas 2014 (Santiago, Ediciones LyD).

Leppe GuZMÁn, Juan Pablo (2013): “Actos intermedios y recurso de protección ambiental”, Revista de Derecho Pontificia Universidad Católica de Valparaíso, No 41.

Montoro Puerto, Miguel (2003): “Tratamiento constitucional de los temas de legalidad ordinaria en el proceso contencioso-administrativo", La justicia administrativa: libro homenaje al Prof. Dr. D. Rafael Entrena Cuesta / coord. por María Jesús Montoro Chiner.

Morales Alzate, John (2010): "La historia del recurso de amparo Constitucional en Alemania”, Revista Principia Iuris, $\mathrm{N}^{\circ} 14$.

Palomo Vélez, Diego (2007): "Amparo Constitucional en España: estudio sobre una experiencia de dulce y agraz", Estudios Constitucionales, Año $5 \mathrm{~N}^{\circ} 1$.

Pierry Arrau, Pedro (1977): "El recurso de protección y lo contencioso administrativo", Revista de Derecho, Universidad de Concepción, N 165 año XLIV.

Pinilla Rodríguez, Francisco (2014): "El deber de sometimiento al procedimiento especial como limitación al recurso de protección ambiental (Corte Suprema)”, Revista de Derecho (Valdivia), vol. $27 \mathrm{~N}^{\circ} 2$.

Sото KLoss, Eduardo (1982): El recurso de protección: origenes, doctrina y jurisprudencia. (Santiago, Editorial Jurídica). 
Urrutia Silva, Osvaldo (2013): "Jurisprudencia nacional, nuevos Tribunales Ambientales y derecho internacional del medio ambiente”, XL Revista de Derecho Universidad Católica de Valparaiso.

VAN WEZEL, Alex (2011): La garantía de tipicidad en la jurisprudencia del tribunal Constitucional. (Santiago, Editorial LegalPublishing).

\section{NORMAS CITADAS}

DFL N 292 de 5 de agosto de 1953, Aprueba Ley Orgánica de la Dirección General del territorio marítimo y de marina mercante.

Ley $\mathrm{N}^{\circ} 16.395$ de 28 de enero de 1966, Fija el texto refundido de la ley de organización y atribuciones de la superintendencia de seguridad social.

DL N 2.222 de 31 de mayo de 1978, Sustituye Ley de Navegación.

DFL N 101 de 29 de noviembre de 1980, Establece el estatuto orgánico de la superintendencia de administradoras de fondos de pensiones, su organización y atribuciones.

DL No 3.538 de 23 de diciembre de 1980, Crea la superintendencia de valores y seguros.

Ley N 17.997 de 19 de mayo de 1981, Ley Orgánica Constitucional del Tribunal Constitucional.

DFL N¹.122 del 29 de octubre de 1981, Fija el texto del Código de Aguas.

Ley $\mathrm{N}^{\circ} 18.410$ de 22 de mayo de 1985 , Crea la superintendencia de electricidad y combustibles.

Ley $\mathrm{N}^{\circ} 18.902$ de 27 de enero de 1990, Crea la superintendencia de servicios sanitarios.

Ley $N^{\circ} 18.916$ de 8 de febrero de 1990, Aprueba Código Aeronáutico.

Ley $\mathrm{N}^{\circ} 18.933$ de 9 de marzo de 1990, Crea la superintendencia de instituciones de salud previsional, dicta normas para el otorgamiento de prestaciones por isapre y deroga el decreto con fuerza de ley $\mathrm{n}^{\circ} 3$, de salud, de 1981.

Ley $\mathrm{N}^{\circ} 19.300$ de 9 de marzo de 1994, Aprueba ley sobre bases generales del medio ambiente.

DFL N 3 de 19 de diciembre de 1997, Fija texto refundido, sistematizado y concordado de la ley general de bancos y de otros cuerpos legales que se indican.

Ley $\mathrm{N}^{\circ} 19.995$ de 7 de enero de 2005, Establece las bases generales para la autorización, funcionamiento y fiscalización de casinos de juego.

Ley $N^{\circ} 20.322$ del 27 de enero de 2009, Fortalece y perfecciona la jurisdicción tributaria y aduanera.

Ley $N^{\circ} 20.417$ de 26 de enero de 2010, Crea el ministerio, el servicio de evaluación ambiental y la superintendencia del medio ambiente.

Ley $\mathrm{N}^{\circ} 20.529$ de 27 de agosto de 2011, Sistema nacional de aseguramiento de la calidad de la educación parvularia, básica y media y su fiscalización.

Ley $\mathrm{N}^{\circ} 20.600$ del 28 de junio de 2012, Crea los Tribunales Ambientales.

Ley $\mathrm{N}^{\circ} 20.720$ de 9 de enero de 2014, Sustituye el régimen concursal vigente por una ley de reorganización y liquidación de empresas y personas, y perfecciona el rol de la superintendencia del ramo. 


\section{JURISPRUDENCIA CITADA}

STC $106 / 1980$

STC 60/1981

Horvath Kiss, Antonio y otros con Comisión Nacional del Medio Ambiente (1997): Corte Suprema, 19 de marzo de 1997 (recurso de protección) rol N² 2684-1997.

Girardi Lavín, Guido y otros Comisión de Evaluación Ambiental (1998): Corte Suprema, 11 de agosto de 1998 (recurso de protección) rol N².684-1998.

STC $151 / 1999$

Requerimiento respecto del Decreto Supremo No 20 del Ministerio Secretaría General de la Presidencia publicado en el Diario Oficial de 12 de abril de 2001 (2001): Tribunal Constitucional, 26 de junio de 2001 (Requerimiento de inconstitucionalidad) rol No 325.

Requerimiento de inconstitucionalidad presentado por doce señores Senadores respecto del Decreto Supremo No 1, del Ministerio de Vivienda y Urbanismo, publicado en el Diario Oficial de 1 de febrero de 2003 (2003): Tribunal Constitucional, 9 de abril de 2003 (Requerimiento de inconstitucionalidad) rol $\mathrm{N}^{\circ} 370$.

Comunidad Indígena Felipe Nitribuala contra Comisión Regional del Medio Ambiente, Región de la Araucanía (2011): Corte Suprema, 17 de junio de 2011 (recurso de protección) rol $\mathrm{N}^{\circ} 4.289-2011$.

Corporación Fiscalía del Medio Ambiente contra Servicio de Evaluación ambiental Región de Aysén (2012): Corte Suprema, 11 de mayo de 2012 (recurso de protección) rol $\mathrm{N}^{\circ} 2.463-2012$.

Asociación Indígena Tragún Mapu Maile Allipen contra Comisión Evaluadora Ambiental, Región de la Araucanía (2012): Corte Suprema, 8 de junio de 2012 (recurso de protección) rol No $1602-2012$.

Rocco Hidalgo Manuel Luiciano y otros contra Directora Regional (S) Servicio Evaluación Ambiental e Intendente (S) III Región Atacama (2012): Corte Suprema, 28 de agosto de 2012 (recurso de protección) rol N 1960-2012.

Inmobiliaria Torre Barón II S.A. contra Dirección de Obras de la Ilustre Municipalidad de Valparaíso (2013): Corte Suprema, 11 de abril de 2013 (recurso de protección) rol $\mathrm{N}^{\circ} 1.946-2013$.

Solís Olguín Gladys y otros con Servicio de Evaluación Ambiental (2013): Corte de Apelaciones de Santiago, 17 de octubre de 2013 (recurso de protección) rol № 24.635-2013.

Ximena Cazorla Cazorla y otros contra Dirección Ejecutiva del Servicio de Evaluación Ambiental (2014): Corte de Apelaciones de Santiago, 23 de septiembre de 2014 (recurso de protección) rol No 31.177-2013.

Comunidad Indigena Juan de Dios Ancamil III contra Comisión Evaluadora Ambiental (2013): Corte Suprema, 21 de octubre de 2013 (recurso de protección) rol Nº 8.6162013.

Junta de Vecinos JJ.VV. Norte contra Comisión de Evaluación Ambiental V Región (2013): Corte de Apelaciones de Valparaíso, 6 de noviembre de 2013 (recurso de protección) rol $\mathrm{N}^{\circ}$ 6.823-2013. 
Lema Keith Guillermo Patricio con Mardones Lara Dalia Ester (2014): Corte Suprema, 26 de febrero de 2014 (Casación en el fondo) rol Nº 1837-2013.

Comunidad Indígena Mariano Millahual y otras contra Comisión Evaluadora Ambiental Región de la Araucanía (2014): Corte Suprema, 3 de abril de 2014 (recurso de protección) rol No 6.427-2014.

Junta de Vecinos JJ.VV. Norte contra Comisión de Evaluación Ambiental V Región (2014): Corte Suprema, 29 de abril de 2014 (recurso de protección) rol N².892-2014.

Comunidad indígena diaguita Yastai de Juntas de Valeriano y otros contra Comisión de Evaluación Ambiental (Cea) (2014): Corte Suprema, 7 de octubre de 2014 (recurso de protección) rol No $11.299-2014$.

Luis Roberto Arévalo Parra, Miriam Santelices Valenzuela, Ana Cáceres Soto, María Valenzuela Guerrero y otros con Curtiembre Rufino Melero S.A también (Curtiembre) representante Javier Melero Urrestarazu y José Enrique León Rodríguez (2014): Corte Suprema, 26 de noviembre de 2014 (recurso de protección) rol N²4.137-2014.

George Winston Rivers Matamala y otros contra Inversiones Estancilla S.A., representante legal Pedro Miguel Ortiz Cuevas (2014): Corte Suprema, 17 de diciembre de 2014 (recurso de protección) rol N 16.634-2014.

Leopoldo David Muñoz de la Parra y otros contra Resolución Exenta $N^{\circ} 128$ de la Comisión de Evaluación de la X Región de los Lagos y otros (2014): Corte Suprema, 30 de enero de 2015 (recurso de protección) rol N²8.745-2014. 